\title{
CYBER STALKING IS A SOCIAL EVIL: FROM THE INDIAN WOMEN'S PERSPECTIVE
}

\author{
Ameema Miftha, Marc Conrad and Marcia Gibson \\ Institute for Research in Applicable Computing \\ The University of Bedfordshire, University Square, Luton, Bedfordshire, UK
}

\begin{abstract}
We discuss the causes and impacts of selected cyber stalking cases against women in India as evidenced from the literature and conducted interviews. We find that the prevailing social and cultural value system and norms in India can prevent women from approaching police or registering legal complaints. The few studies to-date in the Indian context, indicate the high prevalence and serious impacts cyber stalking has on the victims' psychological and physical state. Our work further confirms this. Moreover, interviewees describe secondary victimizations experienced via the actions of friends and relatives. We observe this to be a form of social punishment stemming from gender-related beliefs and attitudes that seem to be normative in India. These secondary victimizations described had far reaching, long term implications, exacerbating the already high levels of distress typically experienced during cases of cyber stalking.
\end{abstract}

\section{KEYWORDS}

Cyber Stalking, India, Social, Cultural, Reputation, Secondary Victimisation

\section{INTRODUCTION}

Cyberstalking involves a continuous process of persistent unwanted behaviours carried out via digital communication devices. The behaviours, such as threatening and abusive messaging, trolling and doxing, are intended to harm the victim and limit their freedoms and privacy (Drebing et al, 2014; Zarina et al, 2016). In India, rapid integration and growth of internet driven devices coupled with the facilitation of communications technologies have contributed to increased cybercrime (Drebing et al, 2014). These technologies can provide anonymity, convenience and opportunities for stalkers to target victims remotely (Kashmiria, 2014).

Cyber stalking is extremely prevalent wherever people use information communication technologies, with women frequently reported as the most commonly victimised group (Shah \& Srivastava, 2014). India is the second largest country in terms of online private information sharing and Indian women and teenagers increasingly use SNS (Kashmiria, 2014; Sadotra and Kour, 2016). However, in contrast to other countries, in India the number of registered complaints is extremely low compared with the expected high prevalence (Kashmiria, 2014; Zarina et al, 2016; Sadotra and Kour, 2016). In this paper we adopt the case study research strategy and summarise findings as evidenced from direct interviews. We focus on the cases of three women and sought to document experiences of cyber stalking in India, as well as circumstances and considerations surrounding decisions made by the women and their families in dealing with it.

\section{CYBERSTALKING IMPACTS \& THE CAUSAL SOCIAL DILEMMA}

Some recent studies (Zarina et al, 2016) suggest the increased rate of 'habitual internet socialisation culture of women' is a major contributing factor to the increased prevalence of cyber stalking. Exponents of Routine Activity Theory (RAT) support this theme and suggest that, the minimisation of internet socialisation habits can reduce cybercrime and severity of impacts against women (Kalia \& Aleem, 2017). 
However, in case of Indian women, the causes and impacts may include additional social and cultural normative beliefs and attitudes. A limited handful of research on the Indian perspective has been conducted. These identify the prevailing socio-cultural values of Indian society as acting to exacerbate the problems (Roy, 2015; Shah \& Srivastava, 2014). In some cases, the impact is such that, it has changed the normal course of life for those targeted. In the majority of cases cyber stalkers go unpunished due to non-registration of complaints with police (Roy, 2015). From the socio-cultural perspective, a major reason for the increased prevalence may be the flawed transition of the traditional "Maa Durga" status of woman to the modern-day woman (Ramona, 2013), positioning of the women within the Indian patriarchal society (Shah \& Srivastava, 2014), poor social perception of the victim and her family members, friends and relatives, fear of lost reputation and fear of secondary victimisation and harassment - including by enforcement authorities (Shah \& Srivastava, 2014; Roy,2015). As a result, Kashimiria (2014) argues secondary victimization magnifies the ordeal of woman victims. In turn, these beliefs and cultural conflicts may contribute towards growth in prevalence of cyber stalking (Roy, 2015; Sadotra and Kour, 2015).

\section{DISCUSSION OF CASE STUDIES}

Below, we summarise and discuss three interviews conducted with women victims of cyber stalking in India:

\subsection{Case Study A}

The victim was in her mid-20s at the time of the stalking. Her neighbour proposed marriage, but she politely declined and they remained friends. One day she received a friend request on Facebook. She did not know the person, but they claimed to work at her company. She began receiving direct messages and asked who the stalker was, however he would avoid the question or ask her to "guess". This victim became alarmed and, "told him I cannot continue chatting with a stranger [...] if he really was from the same company, why was he hiding his identity? I stopped talking to him". She started to receive "thousands" of Facebook and SMS messages. The victim felt, "uncomfortable" and "disturbed". The messages contained information about what she was wearing and her movements - it was clear the stalker was someone in close proximity. The victim also started to receive silent calls on the landline. Finally, it became too much and she approached her father for help. The family investigated and concluded it had been the neighbour all along. When asked if legal action was taken, the victim said her parents: "thought it would bring bad name to our family's reputation. Also the fact that he was our neighbour, they did not do too much about it". Further, "It's very hard to hide things from neighbours, relatives and people around you. You know how things spread like fire in our culture and people start gossiping. My parents thought it was a good move to send me to Malaysia for a change". The victim was made to leave her job and went to live with family in Malaysia. She found a new job and got engaged. The pair spoke on the phone daily. As they became closer, she told her fiancé about the cyber stalking incident. After a short time, the fiancé's family called and broke off their engagement.

At the time of the interview, the victim's family were advising her to marry her stalker. The interview ends with the victim expressing her regret in talking about the cyber stalking, especially with her parents and ex-fiancé. The case highlights attitudes within Indian society, here the liability is placed on the female. Especially the patriarchal makeup of the society is such that, behaviours like Eve-teasing and female-harassment are often considered as acceptable. In many families, such male behaviours are largely excused.

\subsection{Case Study B}

The victim in her teens, had earned a place at a prestigious college and was in her first year. She received an SMS from an unrecognised number. Her friends said they would message the number too for fun. Although it began that way, the volume of messaging became overbearing. She would wake up with her inbox completely full of messages. The messages became constant leaving her feeling "uncomfortable" - she told the stalker to stop. At this point he revealed his romantic interest, but she told him she was only interested in being friends. The stalker then told her he knew her in person and that she had a boyfriend. The messages continued with increasingly detailed information about the victim's activities. The stalker began to threaten to blackmail the 
victim, saying he would inform her parents about the boyfriend. The victim feared her parents would stop her going to college if they were to find out. She confided in her boyfriend who messaged the stalker using her phone, asking to meet - the stalker agreed. The victim was shocked to realise the stalker was her car driver. The boyfriend and his friends attacked the stalker outside the college, at the time everyone was leaving - this led the victim to feel embarrassment. The college watchmen came and police called, everyone knew about the incident. The college contacted the parents, leading to many arguments and tension at home. The parents did not allow the victim to go to college for over 3 weeks. They did not show concern regarding the cyber stalking and were angry the victim had a boyfriend. In her words: "I was very depressed, I went through all of things without my fault. I was regretting now for replying to those messages and taking it easily. I lost my weight, hair and felt very ashamed going back to college". The parents arranged for the victim to be married to a man in Canada. Because everyone knew what had happened, her parents felt she would not be able to get a good marriage proposal in India - "right society, reputation, community, culture, all these things are more important than your feelings. So I got engaged.". "I like India, but now I will have to live the rest of my life in Canada". After everything that had happened, she said she felt lucky at least she was able to continue her studies, although she felt the reason was because her fiancé's parents might become suspicious if she suddenly stopped. It was important to keep what happened a secret from them.

This is another example of secondary victimization resulting from fear of reputation loss and social attitudes. Even after the identification of the stalker, the victims had to succumb to pressure and remain silent about their experiences. Joshi (2013) argues that such incidences only substantiate the notions on RAT as the flawed socio-cultural value system pulls down the guardianship. The opportunity becomes increased as the female victim avoids reporting the case, due to lost reputation and security. Secondary victimization of this sort creates questions regarding women's safety and freedoms in Indian society.

\subsection{Case Study C}

The victim was in her twenties and recalls being very happy with their life at that time, especially career-wise. Problems began after accepting a Facebook friend request. Although the victim did not know the stranger, she felt she was "mature" enough and there was no harm in accepting. The two began messaging, with conversations described as "casual". Later, the messages began to change and are described as, "stupid". The precise nature is not further clarified, but they were unwanted. Friends advise the victim not to worry and to ignore the messages. The strategy fails and the victim blocks the stalker, at which point, she starts to receive text messages on her phone from an unknown number. The messages include details of daily movements and activities -- the stalker was someone she knew. She describes this as a, "horrible feeling not knowing who my stalker was and feeling that I was being watched continuously, on one side I would want myself to be strong, but on the other side I was scared and frightened". When asked why she did not confide in her parents who may have been able to help, she explains it took a lot of convincing for her parents to allow her to work, especially night shifts and being sure her parents would not allow her to continue if they were to find out. The victim reported feeling, "afraid to leave the house" and "very depressed". Eventually a friend advised her to ask her (male) cousin for help. The cousin and his friends eventually expose the stalker as a work colleague of the victim. However, the cousin then took advantage of the situation by telling everything to her parents. The victim's manager offered to take the matter further, but on the advice of her parents the stalker was left with only a warning. The incident was not reported to police and no further action taken. People (including friends and family) kept reminding the victim of what had happened, this led the parents, fearing reputation loss, to arrange for her to marry her cousin. In the victim's words: "I would have had lots of options, my job, my career [...] I had to leave everything because I was cyber stalked [...] everyone around us knew [...] my parents thought marrying my cousin was the best thing to do".

In this case, the actions of the stalker lead to suffering for the victim but so too, did the actions of family members, legal problems, there are challenges on the social side that make it very difficult for the victims Kashimiria (2014). In India the law considers direct negative effects of cyber stalking cases to determine what (if any) punishment is taken (Shah \& srivastava, 2014; Roy, 2015). However, these interviews along with related work reveal the situation is more complicated, due to the likelihood of secondary victimisation. 


\section{CONCLUSION}

We focused on the experiences of three women victims of cyber stalking in India. We observe that there seems to be a limited attitudinal transition between the concept of the "traditional Indian woman" and that of contemporary reality. Attitudes toward women lead to various negative effects in their lives - particularly of those unfortunate enough to become victims of cyber stalking. Lack of awareness regarding cyber stalking impact, conservative beliefs regarding the position of women within patriarchal society and the importance of familial reputation, lead family members to make seemingly well-intentioned decisions on behalf of women. However, these measures often had far reaching, long term implications and curtailed the women's choices and freedoms; acting as a secondary form of social punishment victims endure. The importance on reputation and related beliefs regarding the culpability of female cyber stalking victims leads to negative stereotypes and creates a situation wherein victims are encouraged to feel shame and to keep quiet.

Perceptions regarding the seriousness of cyber stalking and issues of secondary victimization are rooted in what are arguably outdated values that are out of step with the modern day realities of the connected world. Initiatives to raise public awareness regarding (i) the seriousness of cyber stalking as a crime and (ii) that communications are increasingly mediated via technologies and that (iii) mere usage of these technologies leads to the possibility of becoming cyber stalked, often through no action or fault on the part of the victim are vitally important. Social reforms should be complemented by preventative legal, technical enforcements and support mechanisms that recognize initial negative impacts and secondary effects. This paper is based on findings of three cases and while it is not intended these be considered conclusive, we do believe they are useful for teasing out some of the complex issues regarding cyber stalking, culture and gender in India.

\section{REFERENCES}

Drebing, H. et al. (2014). Cyberstalking in a Large Sample of Social Network Users: Prevalence, Characteristics, and Impact upon Victims. Cyberpsychology, Behavior and Social Networking, Volume 17.

Joshi, D. (2013). India's Criminal Law Amendment To Include Cyber Stalking, Harassment And Voyeurism, Centre for Internet and Society. (Online) Available at: http://www.medianama.com/2013/04/223-criminal-law-amendment-toinclude-cyber-stalking-harassment-and-voyeurism-cis-india/ [Last accessed $21^{\text {st }}$ Feb 2019

Kalia, D. and Aleem, S. (2017). Cyber Victimization Among Adolescents: Examining the Role of Routine Activity Theory, Journal of Psychosocial Research Vol. 12, No. 1, 2017. pp. 223-232.

Kashmiria, S. (2014), Mapping Cyber Crimes against Women in India, International Research Journal of Commerce and Law (IRJCL) Volume -1, Issue -5

Ramona, L. CECIU, (2013), "The Architectonics of Corporeal and Textual Selves: From Durga via Banalata Sen to the Virtual Indian Woman”, Asia Studies I (XVII), 1(2013), pp. 65-90,

Roy, P.K. (2015), why online harassment goes unpunished in India, article Available: http://www.bbc.com/news/worldasia-india-33532706 [Last accessed 23rd Feb 2019].

Sadotra, P and Kour,J. (2015), The Technical and Legal Perspective of Cyber Stalking. International journal of research pedagogy and technology in education and movement sciences vol. 03, issue. 03,

Shah, T and Srivastava, T. (2014), "Indian Women at Risk in the Cyber Space: A Conceptual Model of Reasons of Victimization", International Journal of Cyber Criminology, Vol 8 Issue

Zarina, V. et al. (2016), Toward the Adaptation of Routine Activity and Lifestyle Exposure Theories to Account for Cyber Abuse Victimization, Journal of Contemporary Criminal Justice, Vol. 32(2) 169-188 